\title{
PUMP-AND-TREAT REMEDIATION OF GROUNDWATER CONTAMI- NATED BY HAZARDOUS WASTE: CAN IT REALLY BE ACHIEVED?
}

\section{E.A. VOUDRIAS}

Accepted: 12/07/01
Department of Environmental Engineering

Demokritus University of Thrace

GR-671 00 Xanthi, Greece

tel: $+30-541-62951$

e-mail: voudrias@env.duth.gr

\begin{abstract}
Pump-and-treat (P\&T) is one of the most common methods for remediation of groundwater contaminated by hazardous wastes. However, this method suffers from serious disadvantages, due a series of subsurface processes. Using experimental data and mathematical model simulations, the role of sorption/desorption and dissolution of non-aqueous phase liquids on the effectiveness of P\&T remediation was examined. The results showed that the remediation of groundwater depends directly on the physical/chemical properties of the contaminants and the hydrogeology of the site. With the exception of water-soluble contaminants occupying relatively small parts of relatively homogeneous and water-permeable geologic media, the remediation of groundwater contaminated by hazardous waste using P\&T is, for all practical purposes, impossible and prohibitively expensive.
\end{abstract}

KEY WORDS: pump-and-treat, groundwater remediation, hazardous waste, bromacil, lindane, DDT, non-aqueous phase liquids

\section{INTRODUCTION}

\section{Pump-and-treat}

Groundwater contaminated with dissolved organic and inorganic contaminants can be pumped out of the aquifer and be treated on the surface of the ground. The treated groundwater can either be returned to the pumped aquifer, or used, or discharged. The treatment method depends on the physical-chemical properties of the contaminants to be removed. This remediation scheme is known as pump-and-treat (P\&T).

P\&T systems are designed to: (1) Hydraulically contain and control the movement of contaminated groundwater and prevent continued expansion of the contamination zone. (2) Reduce dissolved contaminant concentrations to comply with cleanup standards and thereby restore the aquifer. (3) Combine the previous two objectives (EPA, 1994). The major advantage of $\mathrm{P} \& \mathrm{~T}$ is that conventional technologies for water and wastewater treatment can be applied for decontamination of the pumped groundwater. These include biological treatment, activated carbon adsorption, air stripping of volatiles, and metal precipitation. P\&T is most effective when it is combined with measures of isolation and/or removal of the contamination source, in order to prevent further contaminant introduction into the groundwater. 
The $\mathrm{P} \& \mathrm{~T}$ remediation requires the passage of sufficient volume of groundwater through the contaminated section of the aquifer, in order to remove not only the dissolved contaminants, but also the ones that desorb from the geologic media, diffuse from zones of low hydraulic conductivity, and dissolve from solid phases or non-aqueous phase liquids (NAPLs).

The volume of groundwater contained in a contaminant plume is known as pore volume. The total volume of groundwater that must be treated on the surface of the ground is determined by the product of the pore volume and the number of pore volumes, which must be pumped, in order to decrease the contaminant concentration in the aquifer to a level equal or lower to the maximum permitted concentration. This is usually the maximum contaminant level $(M C L)$, defined on the basis of toxicity. P\&T systems are usually designed to remove 0,3-2 pore volumes of the contaminated section of the aquifer per year (EPA, 1994). Pumping at higher rates may be limited by low permeability of some sections of the aquifer or interphase mass transfer. The remediation time may be approximated by the comparison of the contaminant rate of removal, the initial mass and the mass remaining in the aquifer at any point in time.

\section{Effectiveness of the P\&T method}

Initially, the objectives of P\&T applications were to reduce contaminant concentrations at levels not exceeding those of drinking water. It was not known, however, whether P\&T is capable of achieving such objectives. Real world experience shows that groundwater remediation by $\mathrm{P} \& \mathrm{~T}$ to drinking water standards may be accomplished, perhaps only for areas with simple geology and relatively simple contamination scenarios. In general, the effectiveness of P\&T systems can be compromised by a number of factors that are related to the contaminants of interest and the characteristics of the site. As a result, it is, usually, impossible to reduce dissolved contaminants to below drinking water standards in reasonable time frames, e.g., less than 10 years at many sites (Mackay and Cherry, 1989; ERA, 1994).

Monitoring contaminant concentrations with time at P\&T sites reveals "tailing" and "rebound" phenomena. "Tailing" refers to the progressively slower rate of dissolved contaminant concentration decline, observed with continued operation of P\&T systems. At many sites, the asymptotic, apparent residual, contaminant concentration exceeds clean-up standards. Another problem is that dissolved contaminant concentrations may "rebound" if pumping is discontinued, after temporarily attaining a clean-up standard.

Tailing and rebound may result from several physical and chemical processes that affect P\&T remediation. These processes include (EPA, 1994):

- Contaminant desorption.

- Non-aqueous phase liquid (NAPL) dissolution.

- Precipitate dissolution.

- Groundwater velocity variation.

- Matrix diffusion.

In this paper we use mathematical model simulations and limited experimental data to discuss two of the most important reasons implicated in the limited effectiveness of P\&T. The discussion is based on various contamination scenarios, which are considered likely to occur in the real world. Specifically, we study the $\mathrm{P} \& \mathrm{~T}$ remediation of groundwater limited: (1) By contaminant desorption from aquifer solids. (2) By dissolution of NAPLs.

\section{RESULTS AND DISCUSSION Contaminant desorption}

In general, the dissolved contaminants move slower than groundwater, due to their sorption onto the geologic media of the aquifer. The retardation due to sorption depends on the physical/chemical properties of the contaminants, as well as the characteristics of the geologic material. The stronger a contaminant is sorbed, the slower will move in groundwater and the more difficult will desorb, resulting in less efficient removal by P\&T. Due to kinetic limitations, the rate of contaminant desorption is reduced, as manifested by a pronounced "tailing" effect. This results in significant increase of remediation time and of the volume of groundwater, which must be pumped and treated on the surface of the ground. Furthermore, if pumping of groundwater is ceased before the total quantity of the contaminant is removed from the aquifer, the contaminant concentration in groundwater might be significantly increased, due to release by slow desorption. This phenomenon is encountered during the pulsed pumping mode of $\mathrm{P} \& \mathrm{~T}$ operation. In order to assess the effect of contaminant desorption on the effectiveness of P\&T remediation, we shall consider a shallow homogeneous aquifer 
Table 1. Input parameters for simulation of P\&T remediation limited by contaminant desorption

\begin{tabular}{|l|c|c|c|}
\hline Parameter & Bromacil & Lindane & DDT \\
\hline Solubility, $\mathrm{mg} \mathrm{l}^{-1}$ & $815^{(1)}$ & $7^{(1)}$ & $0,0055^{(2)}$ \\
\hline $\log K_{o c}$ & $1,85^{(3)}$ & $2,96^{(2)}$ & $4,38^{(2)}$ \\
\hline$f_{o c}$ & 0,009 & 0,009 & 0,009 \\
\hline$K_{d}, \mathrm{ml} \mathrm{g}^{-1}$ & 0,64 & 8,2 & 216 \\
\hline$\varepsilon$ & 0,3 & 0,3 & 0,3 \\
\hline$\varrho_{b}, \mathrm{~g} \mathrm{~cm}^{-3}$ & 1,85 & 1,85 & 1,85 \\
\hline $\mathrm{R}$ & $1,5^{(4)}$ & $52^{(5)}$ & $1330^{(5)}$ \\
\hline Groundwater velocity for remediation, $\mathrm{cm} \mathrm{d}^{-1}$ & 13,7 & 13,7 & 13,7 \\
\hline$a_{x}, \mathrm{~cm}$ & $10^{(6)}$ & $10^{(6)}$ & $10^{(6)}$ \\
\hline Length of contaminated zone, $\mathrm{m}$ & 10 & 10 & 10 \\
\hline Total width of capture zone, $\mathrm{m}$ & 100 & 100 & 100 \\
\hline Aquifer section pore volume, $\mathrm{m}^{3}$ & 700 & 700 & 700 \\
\hline
\end{tabular}

(1) Worthing (1987)

(2) LaGrega et al.(1994)

(3) Watts (1997)

of small but constant thickness, contaminated by the pesticides bromacil, lindane, and DDT, which were disposed of illegally in a waste dump. The remediation plan of this aquifer includes source removal, followed by $\mathrm{P} \& \mathrm{~T}$ remediation of the contaminated groundwater, until the dissolved contaminant concentrations are reduced by $95 \%$, based on their maximum concentration values measured. We shall compute the expected remediation time for a contaminated section $10 \mathrm{~m}$ long, $100 \mathrm{~m}$ wide, and $2 \mathrm{~m}$ thick. This section was located close to the source and contains the highest dissolved pesticide concentrations, $C_{o}$, uniformly distributed.

The P\&T remediation is accomplished by employing a series of fully penetrating wells, positioned on a straight line and covering the entire width of the contaminated section. This well arrangement secures a one-dimensional uniform flow in the contaminated section of the aquifer. The contaminant concentration in the wells can be simulated with the one dimensional advectiondispersion-sorption equation:
(4) Determined experimentally

(5) Determined from Equations 2 and 3

(6) Gelhar et al. (1992)

where: $C=$ contaminant concentration, $\mathrm{M} \mathrm{L}^{-3}$

$t=$ time, $\mathrm{t}$

$x=$ longitudinal Cartesian coordinate, $\mathrm{L}$

$V=$ average pore velocity in the $\mathrm{x}$ direction, $\mathrm{L} \mathrm{t}^{-1}$

$R=$ retardation factor

$D=$ hydrodynamic dispersion coefficient in the $\mathrm{x}$ direction, $\mathrm{L}^{2} \mathrm{t}^{-1}$

$K_{d}=$ linear sorption coefficient, $\mathrm{L}^{3} \mathrm{M}^{-1}$

$\varrho_{b}=$ bulk density of the geologic medium, $\mathrm{M} \mathrm{L}^{-3}$

$\varepsilon \quad=$ porosity of the geologic medium

$K_{o c}=$ linear sorption coefficient normalized for organic carbon content, $\mathrm{L}^{3} \mathrm{M}^{-1}$

$f_{o c}=$ fraction of organic carbon 


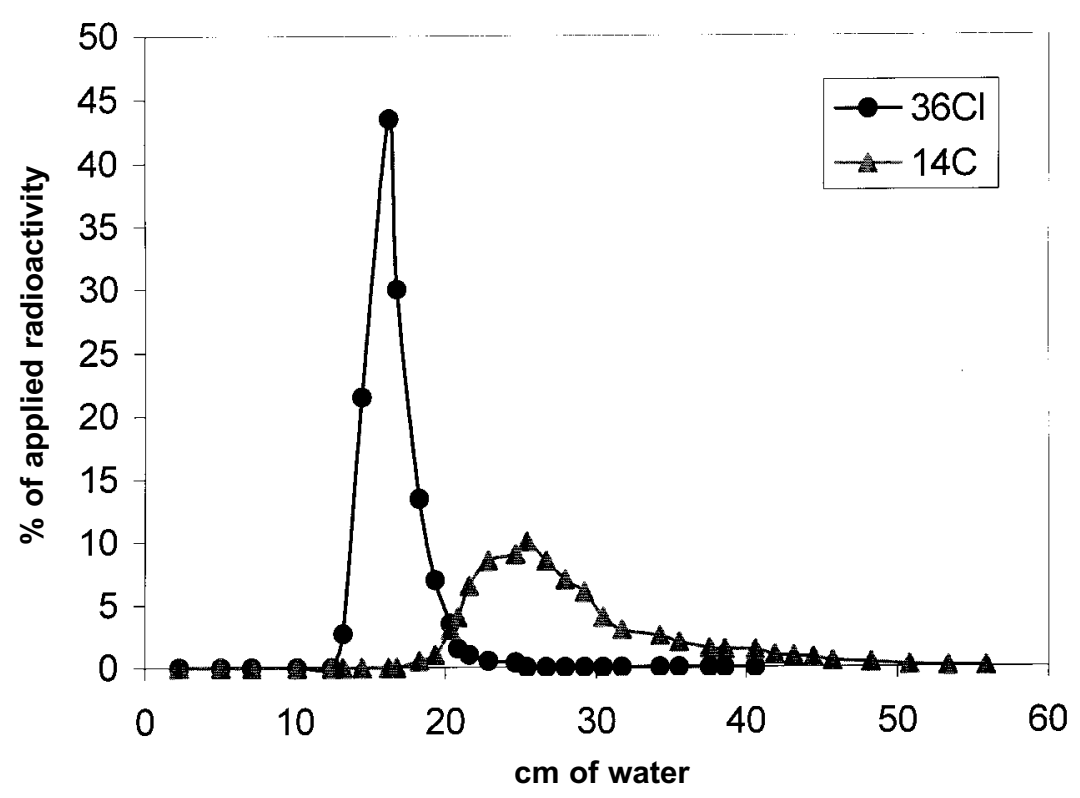

Figure 1. Experimental determination of bromacil retardation factor, using a soil column.

The simulation parameters are presented in Table 1 . The retardation factors used in the simulation are 1,5 for bromacil, 52 for lindane, and 1330 for DDT (Table 1). Those for lindane and DDT were computed based on the respective linear sorption coefficient values and the organic carbon fraction of the aquifer, $f_{o c}=0,009$, using Equations 2 and 3 (Karickhoff, 1984). The retardation factor for bromacil was determined experimentally, by comparing elution times of $\mathrm{Na}^{36} \mathrm{Cl}$ and $\left[2-{ }^{14} \mathrm{C}\right]$-labeled bromacil, which were added to the top of the soil column of interest. The soil column was $30 \mathrm{~cm}$ long and $5 \mathrm{~cm}$ in diameter. Eluate fractions were analyzed by Liquid Scintillation Counting and the constructed eluate pulse curves for ${ }^{14} \mathrm{C}$ and ${ }^{36} \mathrm{Cl}^{-}$were used to determine the retardation factor (Figure 1).

The hydrodynamic dispersion coefficient was determined using:

$D=\alpha_{x} V+\tau D_{m}$

where: $\alpha_{x}=$ longitudinal dispersivity, $\mathrm{L}$

$\tau=$ medium tortuosity

$D_{m}=$ molecular diffusion coefficient, $\mathrm{L}^{2} \mathrm{t}^{-1}$

Estimates of the longitudinal dispersivity, $\alpha_{x}$, were obtained from Gelhar et al. (1992). During the remediation phase, the average pore velocity of groundwater used in the simulation was $50 \mathrm{~m} \mathrm{yr}^{-1}$ $\left(13,7 \mathrm{~cm} \mathrm{~d}^{-1}\right)$. Due to the relatively high groundwater velocity during the remediation phase, the diffusion component of the hydrodynamic dispersion coefficient was ignored, because it was three orders of magnitude lower than the mechanical dispersion component.

Using the appropriate initial and boundary conditions, the analytical solution of Eq. 1 (van Genuchten and Alves, 1982) and the input parameters of Table 1, we simulated the remediation by P\&T of the aquifer section (Figure 2). The maximum contaminant level for each pesticide in groundwater was set arbitrarily at 5\% of the respective maximum concentration value detected. The remediation time for each pesticide follows the order of the respective retardation factor and equals 1 and 14 years, for bromacil and lindane, respectively. The remediation time for DTT is several hundred years, way out of the 25-year simulation range performed for this particular problem. Considering a total width of the capture zones of the pumping wells equal to $100 \mathrm{~m}$ and aquifer thickness equal to $2 \mathrm{~m}$, the volume of groundwater that must be pumped and treated above ground will be approximately $3500 \mathrm{~m}^{3}$ (or 5 pore volumes) and $49000 \mathrm{~m}^{3}$ (or 70 pore volumes) for bromacil and lindane, respectively. This volume refers only to the $10 \mathrm{~m}$ long aquifer section considered here and not the entire contaminated 


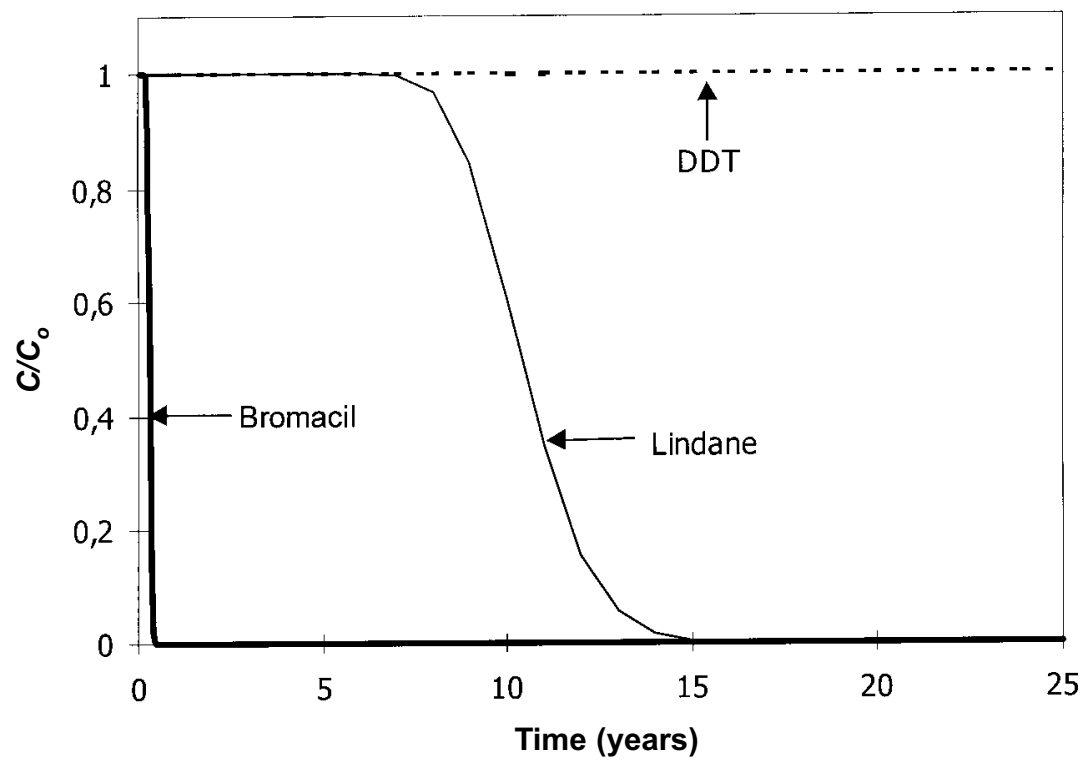

Figure 2. The effect of sorption-desorption on pump and treat remediation of groundwater contaminated by bromacil, lindane, and DDT.

area. For comparison purposes, one void volume (pore volume) of the aquifer section is only $10 \times$ $100 \times 2 \times 0,35=700 \mathrm{~m}^{3}$. Remediation of the entire plume (up and downgradient of the pumping wells) would require a much larger volume to be pumped and treated above ground. In general, for large contaminant plumes, this volume may be many thousand or million $\mathrm{m}^{3}$, rendering $\mathrm{P} \& \mathrm{~T}$ remediation prohibitively expensive, if not impossible. Increase of organic carbon fraction of the aquifer material would increase the value of $\mathrm{R}$ and, accordingly, the aquifer remediation time.

\section{NAPL dissolution}

Non-aqueous phase liquids (NAPLs) are liquids immiscible with water. When a NAPL is released in the vadose zone in sufficient quantity, a portion of it will become immobilized and the remaining fluid will continue to move downward. Upon reaching the water table, NAPLs heavier than water (DNAPLs, e.g., chlorinated solvents) tend to move downward, leaving behind "blobs" or "ganglia" of trapped residual. The movement continues, until they either encounter an impermeable zone or spread out to the point where the pressure head is depleted and the NAPL becomes totally immobilized, as residual. The NAPLgroundwater interface may become unstable, and this instability is manifested by "fingers" of NAPL penetrating the aquifer (Schwille, 1988). When fingers reach an impermeable zone, they can move laterally and follow the slope of the barrier. Thus, pools of NAPLs at near saturation will form on layers of lower permeability media within an aquifer, or on the bottom of an aquifer, after displacing most of the pore water (Mackay and Cherry, 1989).

NAPLs lighter than water (LNAPLs, e.g., petroleum products) tend to spread laterally and form a pool floating at the capillary fringe, above the water table (Schwille, 1988; Voudrias and Yeh, 1994). In addition, the water table moves up and down in response to seasonal recharge and discharge and local pumping. As a result, a zone contaminated by a lighter-than-water NAPL will extend over the range of water table fluctuation. When pools or ganglia occur in the subsurface, groundwater contamination will result from the NAPL dissolving in the water and being transported to a well at concentrations exceeding drinking water standards. Although the NAPL solubility is, generally, low, it is frequently several orders of magnitude higher than the maximum contaminant level for drinking water. Therefore, a small amount of NAPL may contaminate a large volume of groundwater. NAPL contamination in groundwater may last for many years or even centuries (Voudrias and Yeh, 1994).

In a series of experiments designed to study the removal of petroleum components or products 
Table 2. Retardation factors, groundwater volume, and groundwater pore volumes required for removal of some jet fuel JP-4 components from the contaminated aquifer section.

\begin{tabular}{|l|r|c|c|c|}
\hline Contaminant & $\boldsymbol{R}_{\boldsymbol{i}}$ & $\begin{array}{c}\text { Solubility } \\
\text { in water at } \mathbf{2 0}{ }^{\circ} \mathbf{C}, \mathbf{~ m g ~ l}^{\mathbf{1}}\end{array}$ & $\begin{array}{c}\text { Volume of } \\
\text { groundwater, } \mathbf{~}^{\mathbf{3}}\end{array}$ & $\begin{array}{c}\text { Number of } \\
\text { pore volumes }\end{array}$ \\
\hline Benzene & 180 & 1780 & 18680 & 180 \\
\hline Toluene & 620 & 515 & 64360 & 620 \\
\hline Xylene & 1850 & $172\left(\right.$ at $\left.25^{\circ} \mathrm{C}\right)$ & 192340 & 1850 \\
\hline Ethylbenzene & 2100 & 152 & 217670 & 2100 \\
\hline n-Hexane & 33540 & 9,5 & 3481140 & 33540 \\
\hline
\end{tabular}

(1) Verschueren (1983)

(toluene, toluene-benzene mixtures, jet fuel JP4), an extremely large number of pore volumes was required (Voudrias et al., 1994). Mass balance calculations showed that removal of pure toluene by $98,6 \%$ by dissolution into groundwater, required 132 pore volumes of groundwater. In the case of benzene-toluene mixtures $(50 \%$ each by weight), 53 pore volumes of groundwater were required for $94,6 \%$ removal of benzene and $88,3 \%$ of toluene, by dissolution into groundwater. The remainder of benzene and toluene would remain in the subsurface for extremely long times, due to significant amount of tailing observed.

In the field, the volume of groundwater required for removal of a specific component from a mixture of NAPLs would be larger than that determined in the laboratory, due to significant dispersion, sorption, and heterogeneity of the aquifer (Voudrias et al., 1994). One order of magnitude approximation for the required amount of groundwater for blob dissolution is given by Equations 5 and 6 (Borden and Piwoni, 1992; Voudrias et al., 1994).

$V_{w i}=R_{i}(P V)$

$R_{i}=1+K_{d i} \frac{\rho_{b}}{\varepsilon^{w}}+\frac{\varepsilon^{o} \rho^{o} \gamma_{i}^{w}}{\varepsilon^{w}\left(M W_{i}\right) S_{i} \gamma_{i}^{o}}$

where: $V_{w i}=$ volume of water to flush compound $\mathrm{i}, \mathrm{L}^{3}$

$P V=$ aquifer pore volume, $\mathrm{L}^{3}$

$R_{i}=$ linear equilibrium retardation factor for compound i, due to partitioning in the solid phase and oil $\varrho_{b}=$ aquifer bulk density, $\mathrm{M} \mathrm{L}^{-3}$

$K_{d i}=$ linear sorption coefficient of compound i, $\mathrm{L}^{3} \mathrm{M}^{-1}$

$w, o=$ superscripts for water and oil (NAPL) phase, respectively

$\varepsilon=$ porosity for water or oil phase

$\gamma_{i}=$ activity coefficient of compound $\mathrm{i}$, for water or oil phase

$\varrho^{o}=$ density of oil phase, $\mathrm{M} \mathrm{L}^{-3}$

$M W_{i}=$ molecular weight of compound i

$S_{i}=$ aqueous solubility of component i in its pure form, $\mathrm{M} \mathrm{L}^{-3}$

Prerequisite for using the above equations is that the organic liquids are always in equilibrium with groundwater and are easily available for dissolution into groundwater.

In order to assess the effect of NAPL blob dissolution on the effectiveness of $\mathrm{P} \& \mathrm{~T}$ remediation, we shall consider a section of an aquifer with dimensions $10 \mathrm{~m} \times 10 \mathrm{~m} \times 3 \mathrm{~m}$ and with total porosity equal to 0,35 . The section has been contaminated with jet fuel JP-4, released from a leaking underground storage tank. The degree of saturation is 0,30 . Considering insignificant contam-

inant sorption $\left(K_{d i}=0\right)$ and $\frac{\gamma_{i}^{w}}{\gamma_{i}^{o}}=1$, the volume

of groundwater and the number of pore volumes required for removal of some JP-4 components is presented in Table 2. The number of pore volumes increases significantly with decreasing constituent solubility, ranging from 180 for benzene to 33540 for n-hexane. Obviously, the required 
Table 3. Input parameters for simulation of P\&T remediation limited by a toluene pool dissolution.

\begin{tabular}{|l|c|c|c|}
\hline Parameter & $\mathbf{L = 1 0 0} \mathbf{~ c m}$ & $\mathbf{L}=\mathbf{5 0 0} \mathbf{~ c m}$ & $\mathbf{L}=\mathbf{1 0 0 0} \mathbf{~ c m}$ \\
\hline$\alpha_{z}, \mathrm{~cm}$ & $0,015^{(1)}$ & $0,05^{(1)}$ & $0,1^{(1)}$ \\
\hline$D_{m}, \mathrm{~cm}^{2} \mathrm{sec}^{-1}$ & $8,46 \times 10^{-6(2)}$ & $8,46 \times 10-6^{(2)}$ & $8,46 \times 10-6^{(2)}$ \\
\hline$\tau$ & $0,7^{(3)}$ & $0,7^{(3)}$ & $0,7^{(3)}$ \\
\hline$\varrho, \mathrm{g} \mathrm{cm}^{-3}$ & $0,866^{(4)}$ & $0,866^{(4)}$ & $0,866^{(4)}$ \\
\hline$C_{s}, \mathrm{~g} \mathrm{~cm}^{-3}$ & $515 \times 10^{-6(5)}$ & $515 \times 10^{-6(5)}$ & $515 \times 10-6^{(5)}$ \\
\hline
\end{tabular}

(1) Gelhar et al. (1992)

(2) Wilke-Chang equation, cited by Li and Voudrias (1994)

(3) de Marsily (1986)

(4) Weast (1974)

(5) Verschueren (1983)

groundwater volume would be much higher in case of significant contaminant sorption $\left(K_{d i}>0\right)$, rendering again $\mathrm{P} \& \mathrm{~T}$ remediation practically impossible.

The dissolved phase concentration arising from dissolution of a NAPL pool in groundwater, under conditions of uniform and steady flow, is described by Equation 7:

$V \frac{\partial C}{\partial x}=D_{z} \frac{\partial^{2} C}{\partial z^{2}} \quad$ with

$D_{z}=\alpha_{z} V+\tau D_{m}$

where: $V=$ average pore velocity in the longitudinal direction, $\mathrm{L} \mathrm{t}^{-1}$

$D_{z}=$ transverse dispersion coefficient in the vertical direction, $\mathrm{L}^{2} \mathrm{t}^{-1}$

$\alpha_{z}=$ transverse dispersivity in the vertical direction, $\mathrm{L}$

$\mathrm{C}=$ dissolved NAPL concentration, $\mathrm{M} \mathrm{L}^{-3}$

$\mathrm{x}=$ longitudinal Cartesian coordinate, $\mathrm{L}$

$\mathrm{z}=$ vertical Cartesian coordinate, $\mathrm{L}$

For the proposed boundary conditions:

$C(0<x \leq L, z=0)=C_{s}$

$C(x, z=\infty)=0$

$C(x=0, z)=0$

where: $L=$ length of the pool, $\mathrm{L}$

$C_{s}=$ NAPL solubility in water, $\mathrm{M} \mathrm{L}^{-3}$
The solution to the above equation is (Hunt et al., 1988; Voudrias and Yeh, 1994):

$C(L, z)=C_{s} \operatorname{erfc}\left[\frac{z}{2\left(D_{z} L / V\right)^{0,5}}\right]$

This model was validated with experimental data by Voudrias and Yeh (1994).

Assuming that the areal dimensions of the pool do not change during the course of the dissolution process, i.e., that dissolution leads to a thinning of the pool, the time to complete dissolution will be:

$\tau=\frac{m}{L W M_{\alpha}} \quad$ with

$M_{\alpha}=C_{s} \varepsilon \sqrt{\frac{4 D_{z} V}{\pi L}}$

$m=L W H \varrho \varepsilon$

where: $\tau=$ pool dissolution time, $\mathrm{t}$

$m=$ mass of NAPL in the pool, $\mathrm{M}$

$L=$ length of the pool, $\mathrm{L}$

$W=$ width of the pool, $\mathrm{L}$

$H=$ height of the pool, $\mathrm{L}$

$M_{\alpha}=$ mass transfer coefficient, $\mathrm{M} \mathrm{L}^{-2} \mathrm{t}^{-1}$

$C_{s}=$ NAPL solubility in water, $\mathrm{M} \mathrm{L}^{-3}$

$\varepsilon=$ aquifer porosity

The expression for the mass transfer coefficient 


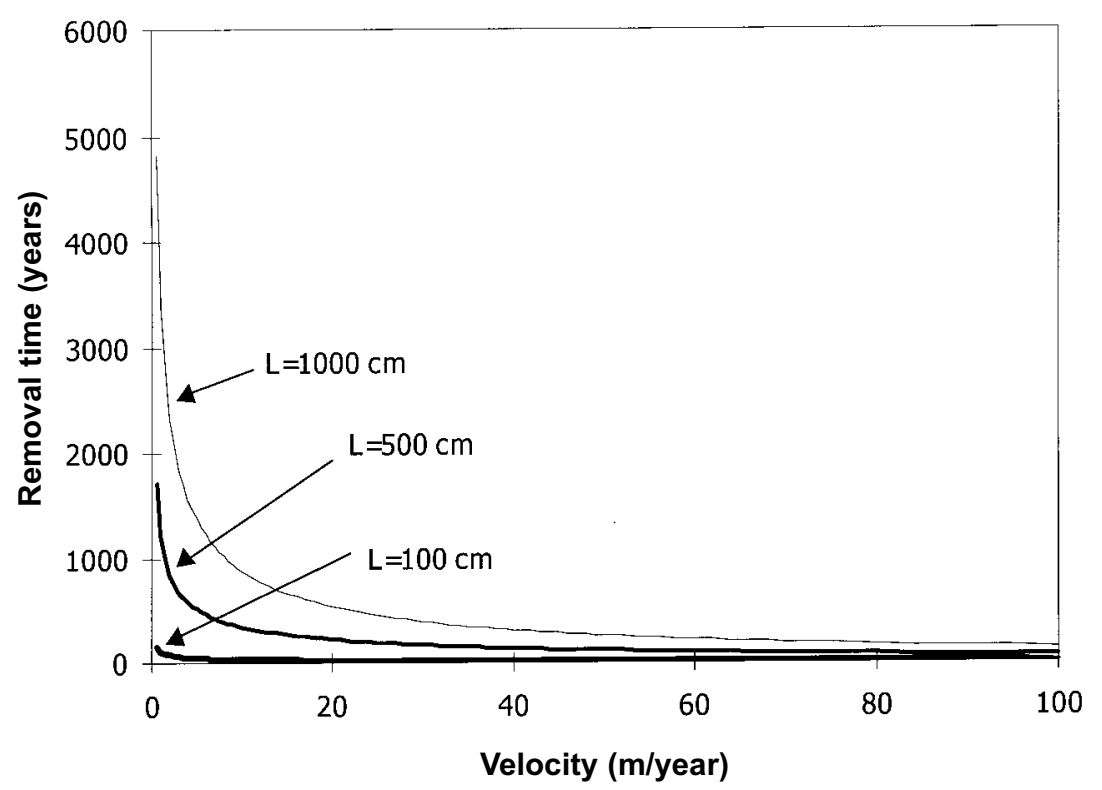

Figure 3. Simulation of toluene pools removal by dissolution into groundwater, as a function of groundwater velocity

(Equation 14) is given by Bird et al. (1960) and Johnson and Pankow (1992).

In order to assess the effect of NAPL pool presence on the effectiveness of P\&T remediation, we shall consider the removal of toluene pools floating at the water table, by dissolution into groundwater. The original lengths of the pools were 100, 500, $1000 \mathrm{~cm}$. The thickness of all pools was considered to be uniform and equal to $1 \%$ of the respective length. Using Equation 13 and the input parameters of Table 3, the respective removal time of the pools was computed. According to Figure 3, the removal time for groundwater velocities $<20 \mathrm{~m} \mathrm{yr}^{-1}$ is of the order of several centuries, which renders the aquifer remediation by P\&T, practically impossible. Similar results were also obtained from a

Table 4. Input parameters for simulation of P\&T remediation limited by NAPL pool dissolution

\begin{tabular}{|l|c|c|c|c|}
\hline Parameter & Benzene & Toluene & $\mathbf{1 , 1 , 2 - T C A}$ & TCE \\
\hline$\alpha_{z}, \mathrm{~cm}$ & $0,05^{(1)}$ & $0,05^{(1)}$ & $0,05^{(1)}$ & $0,05^{(1)}$ \\
\hline$D_{m}, \mathrm{~cm}^{2} \mathrm{sec}^{-1}$ & $9,59 \times 10^{-6(2)}$ & $8,46 \times 10^{-6(2)}$ & $8,11 \times 10^{-6(3)}$ & $8,43 \times 10^{-6(3)}$ \\
\hline$\tau$ & $0,7^{(4)}$ & $0,7^{(4)}$ & $0,7^{(4)}$ & $0,7^{(4)}$ \\
\hline$\varrho, \mathrm{g} \mathrm{cm}^{-3}$ & $0,879^{(5)}$ & $0,866^{(5)}$ & $1,44^{(6)}$ & $1,46^{(6)}$ \\
\hline$C_{s}, \mathrm{~g} \mathrm{~cm}^{-3}$ & $1780^{(7)}$ & $515 \times 10^{-6(7)}$ & $4500 \times 10^{-6(6)}$ & $1100 \times 10^{-6(6)}$ \\
\hline$L, \mathrm{~cm}$ & 500 & 500 & 500 & 500 \\
\hline
\end{tabular}

(1) Gelhar et al. (1992)

(2) Wilke-Chang equation, cited by Li and Voudrias (1994)

(3) Lyman et al. (1990)

(4) de Marsily (1986)

(5) Weast (1974)

(6) Schwille (1988)

(7) Verschueren (1983) 


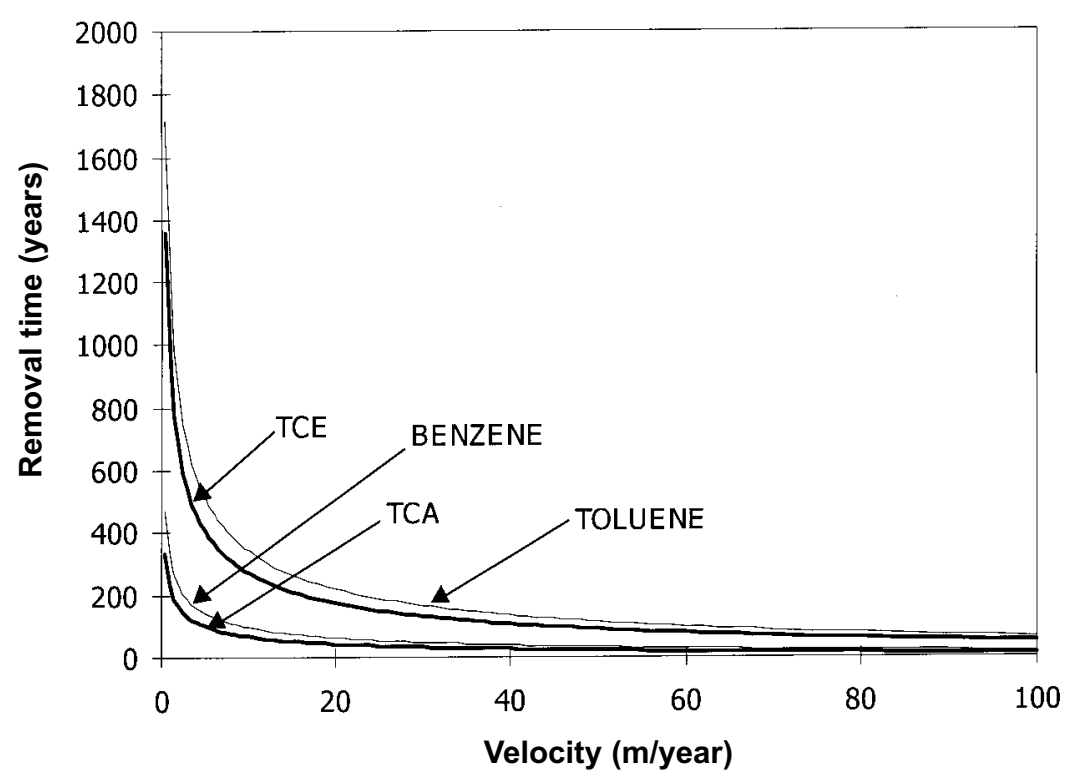

Figure 4. Simulation of NAPL pools removal by dissolution into groundwater, as a function of groundwater velocity

series of other NAPLs, occurring, often, in groundwater. In the latter case, it was observed that the pool removal time decreased (Figure 4) with increase of solubility of the respective NAPL: Toluene $<1,1,2$-Trichloroethylene (TCE) $<$ Benzene $<1,1,2$-Trichloroethane (TCA). The results of Figure 4 were produced from Equation 13, using the parameters of Table 4.
The time required for the removal of a NAPL pool is always much larger than the time required when the NAPL is in the form of ganglia. This is due to the much larger interface and, therefore, faster mass transport, occurring in the latter case. For complete NAPL removal, the dissolution time must be added to the desorption time of the dissolved contaminants, due to the tailing effects.

\section{REFERENCES}

Bird, R.B, Stewart, W.E. and Lightfoot, E.N. (1960), Transport phenomena, pp. 541, John Wiley and Sons, New York

Borden, R.C. and Piwoni, M.D. (1992), Hydrocarbon dissolution and transport: A comparison of equilibrium and kinetic models, Journal of Contaminant Hydrology, 10, 309-323

de Marsily, G. (1986), Quantitative hydrogeology, Academic Press, Orlando, Florida, pp. 440

EPA (1994), Methods for monitoring pump-and-treat performance, Environmental Protection Agency, EPA/600/R-94/123, Washington D.C.

Gelhar, L.W., Welty, C. and Rehfeldt, K.R. (1992), A critical review of data on field-scale dispersion in aquifers, Water Resources Research, 28, 1955-1974

Hunt, J.R., Sitar, M., and Udell, K.S. (1988), Water Resources Research, 24, 1247-1259

Johnson, R.L and Pankow, J.F. (1992), Dissolution of dense chlorinated solvents into groundwater. 2. Source functions for pools of solvents, Environmental Science and Technology, 26, 896-901

Karickhoff, S.W. (1984), Organic pollutant sorption in aquatic systems, Journal of Hydraulic Engineering, 110, 707735

FaGrega, M.D., Buckingham, P.L. and Evans, J.C. (1994), Hazardous waste management, McGraw-Hill, New York

Li, C. and Voudrias, E.A. (1994), Migration and sorption of jet fuel cycloalkane and aromatic vapors in unsaturated soil, Environmental Progress, 13, 290-297

Lyman, W.J., Reehl, W.F. and Rosenblatt, D.H. (1990), Handbook of chemical property estimation methods, American Chemical Society, Washington D.C. 
Mackay, D. and Cherry, J.A. (1989), Groundwater contamination: Pump-and-treat remediation, Environmental Science and Technology, 23, 630-636

Schwille, F. (1988), Dense chlorinated solvents in porous and fractured media-model experiments, J.F. Pankow, translator, Lewis Publishers, Boca Raton, Florida

van Genuchten, M.Th. and Alves, W.J. (1982), Analytical solutions of the one-dimensional convective-dispersive solute transport equation, Technical Bulletin No. 1661, U.S. Department of Agriculture

Verschueren, K. (1983), Handbook of environmental data of organic chemicals, 2 ${ }^{\text {nd }}$ Edition, van Nostrand Reinhold Company, New York

Voudrias, E.A., Nzengung, V., and Li, C. (1994), Removal of light nonaqueous phase liquids (LNAPLs) by aquifer flushing, Waste Management, 14, 115-126

Voudrias, E.A. and Yeh, M.F. (1994), Dissolution of a toluene pool under constant and variable hydraulic gradients with implications for aquifer remediation, Ground Water, 32, 305-311.

Watts, R.J. (1997), Hazardous wastes, John Wiley and Sons, New York.

Weast, R.C. (1974), Handbook of chemistry and physics, 55 ${ }^{\text {th }}$ Edition, CRC Press, Cleveland, Ohio.

Worthing, C.R. (1987), The pesticide manual, $8^{\text {th }}$ edition, The British Crop Protection Council. 